\title{
TRANSMISSÃO DE PREÇOS AO LONGO DAS CADEIAS PRODUTIVAS DO BRASIL
}

\author{
Dienice Ana Bini* \\ Mirian Oliveira de Souza** \\ Mário Duarte Canever*** \\ Regis Augusto Ely***
}

\section{Resumo}

Essa pesquisa avaliou a transmissão de preços entre diferentes elos de cadeias produtivas do Brasil. Especificamente, avaliou-se a transmissão do preço do petróleo para os preços dos três fertilizantes básicos (cloreto de potássio, superfosfato simples e sulfato de amônia) e das commodities (milho, soja e frango), bem como as transmissões entre esses produtos. Os resultados revelam que os preços de fertilizantes e commodities apresentam uma baixa dependência do preço do petróleo. Variações no preço do milho e da soja são parcialmente repassadas para o preço dos fertilizantes e vice-versa. Variações no preço da soja são transmitidas para o preço do milho. Os preços do milho e do frango podem ser considerados mutuamentedependentes. O preço da soja éaltamente exógeno, não sendo influenciado pelos demais produtos.

Palavras chaves: Petróleo, fertilizantes, VEC.

\begin{abstract}
This research evaluated a transmission of prices between different links of productive chains in Brazil. Specifically, we evaluated a transmission of the price of oil to the prices of three basic fertilizers (potassium chloride, ammonium sulphate, and simple superphosphate) and commodities (corn, soybean and chicken), as well as transmissions between these products. The results reveal that fertilizer and commodity prices are a low dependence on the price of oil. Variations in the price of corn and soybeans are partially passed on to the price of fertilizers and vice versa. Variations in the price of soybean are transmitted to the price of corn. Prices of corn and chicken can be mutually dependent. The price of soybean is highly exogenous and is not altered by other products.
\end{abstract}

Key words: Oil, fertilizers, VEC.

Código J EL: Q02; Q11; Q13

\section{Introdução}

O Brasil é um importante supridor de commodities, tanto para as exportações quanto para o seu próprio consumo. Dos muitos produtos que o país produz, merece destaque a carne de frango. Além do Brasil estar entre os maiores produtores e consumidores desta carne, devido, entre outros fatores, à maior

\footnotetext{
* Escola Superior de Agricultura Luiz de Queiroz - Esalq/ USP

** Empresa Brasileira de Pesquisa Agropecuária - Embrapa

*** Universidade Federal de Pelotas - UFPel
} 
competitividade no mercado internacional, conquistada pelo menor custo de produção, o país se mantém líder nas exportações mundiais desde 2004 (ABPA, 2016).

No mercado interno, o preço da carne de frango é estratégico, pois seu crescimento impacta direta e negativamente os orçamentos familiares (Oliveira Júnior et al. 2014). Assim, é relevante conhecer os principais fatores que interferem nas variações deste preço para o estabelecimento de políticas econômicas emitigação dos efeitos nocivos sobre a alimentação das famílias. Para os autores citados, apesar de haver influência de variações cambiais e de fatores climáticos e biológicos, as maiores alterações nos preços desta carne são ocasionadas pela movimentação dos preços dos insumos de produção.

Considerando que o milho e o farelo de soja são os principais insumos na produção de ração animal e que esta representa em torno de $65 \%$ dos custos de produção do frango de corte (Embrapa, 2017), há fortes razões para acreditar-se que variações nos preços dessas commodities agrícolas geram variações nos preços da carne de frango. Além disso, como o petróleo é utilizado como insumo na produção de milho e soja, tanto direta (abastecimento de meios de produção e transporte) quanto indiretamente (na produção e distribuição de fertilizantes e defensivos), acredita-se que o aumento do seu preço também contribui para a elevação nos preços destas commodities e subsequentemente da carne de frango.

Nesse contexto, o objetivo deste artigo é verificar se o canal de transmissão do preço internacional do petróleo para os preços domésticos das commodities, milho, soja e frango ocorre de forma indireta, ou seja, via preço dos fertilizantes básicos (cloreto de potássio, superfosfato simples e sulfato de amônia). Pressupõe-se que variações no preço dos insumos sejam repassadas para os elos seguintes da cadeia produtiva, via repasses dos preços dos fertilizantes para os grãos, e dos grãos para a carne de frango e suas possíveis relações inversas.

O estudo é focado em importantes atividades do agronegócio brasileiro, o qual responde por cerca de 22\% do PIB nacional (CEPEAa, 2014) e se destaca pela eficiência produtiva, pela geração de empregos e superávits comerciais do País (CEPEAb, 2014). Além disso, devido ao Brasil ter ampla inserção no mercado internacional deprodutos agrícolas, conhecer estas transmissões são importantes tanto para os agentes privados no estabelecimento de estratégias de compra e venda, como para o governo no estabelecimento de políticas competitivas de importação e exportação.

\section{Embasamento Teórico e Empírico}

Mudanças nos preços do petróleo afetam a maioria dos setores econômicos dos países (Baffes 2007). No caso da agricultura, no entanto, a literatura nacional e internacional não é uníssona em confirmar a existência de transmissão dos choques dos preços do petróleo para as principais commodities agrícolas. Para exemplos de trabalhos que confirmam a existência desta transmissão ver Hanson et al. (1993); Chen et al. (2010). Por outro lado, a hipótese de transmissão foi refutada nos resultados obtidos por Zhang \& Reed (2008); Mutuc et al. (2010), entre outros. Adicionalmente, se de fato o impacto do petróleo nas commodities agrícolas é real, este parece mais frequente nos estudos que consideram séries de 
preços mais recentes (Nazlioglu e Soytas 2011; Reboredo 2012). Especialmente para aqueles com dados a partir de 2005 (Chen et al. 2010; Avalos 2014), sendo a expansão da produção de etanol, a partir do milho, um dos canais pela qual essa transmissão pode ocorrer.

No caso brasileiro os preços parecem correlacionados (Figura 1). É notório queas séries apresentam movimento similares, como por exemplo, todas as séries sofrem uma elevação no ano de 2008, com posterior decréscimo até 2009. Observa-se que o aumento no preço do petróleo em 2007 parece preceder o aumento nas demais commodities. Porém, essa tendência não se repete em 2014, assim como o preço do frango não acompanhou aumento no preço do milho, e posteriormente o aumento da soja, em 2016.

Entretanto, espera-se que o entrelaçamento dos preços do petróleo com as commodities agrícolas seja menor no Brasil do que em nível internacional. No Brasil o etanol é oriundo da cana de açúcar, enquanto nos demais países (especialmente nos EUA) o etanol é oriundo do milho que conecta os dois mercados. Assim, no Brasil, variações no preço do petróleo impactam os custos de produção das commodities agrícolas, mas dificilmente acirra a competição pelo fator de produção terra, já que a cana de açúcar é produzida predominantemente no estado de São Paulo e no Nordeste, enquanto a produção de grãos está localizada nos três estados do Sul e no Centro-Oeste brasileiro. Então, no Brasil, espera-se que o impacto da variação dos preços do petróleo nos preços dos grãos e da carne de frango se dê pela via dos custos de produção nas fazendas e no transporte dos insumos e da produção, mas não pelo acirramento da competição pelo fator de produção terra.

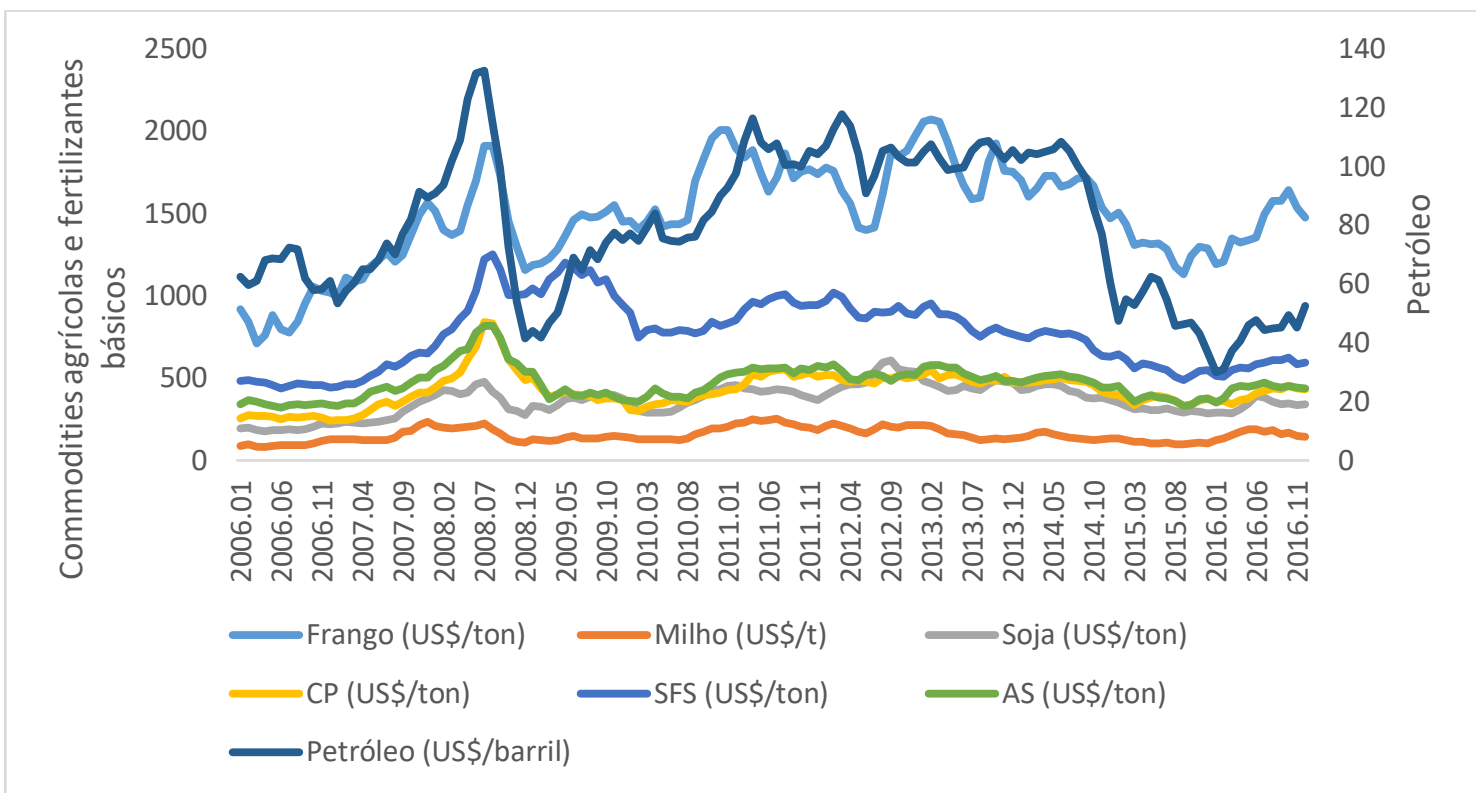

Figura 1- Evolução mensal dos preços dos fertilizantes básicos (cloreto de potássio (CP), superfosfato simples (SFS) e sulfato de amônia (AS)), milho, soja e frango no mercado internacional em US\$/toneladas e preço internacional do petróleo em US\$/barril de janeiro de 2006 a dezembro de 2016.

Fonte: Elaborada pelos autores com base nos dados IEA, IPEADATA e FMI. 
Os fertilizantes utilizam em sua composição derivados de petróleo ou substitutos destes (Baffes 2007, 2010; Abbott et al. 2008; Arshad \& Hameed 2009; Woods et al. 2010; Liu 2013). Assim variações nestes preços são repassados para os insumos agrícolas. A variação nos preços do petróleo pode também se transmitir para as commodities agrícolas pelo impacto nos custos dos transportes, tanto para a internalização dos insumos até as regiões produtoras, quanto para fazer o caminho inverso nas exportações das próprias commodities. No Brasil, o modal de transporte mais utilizado é o rodoviário, o que onera os custos por unidade transportada, dado a baixa eficiência em longas distâncias.

Em nível internacional, Baffes (2007), confirma que os preços mundiais do petróleo afetam os preços dos fertilizantes e do transporte. Abbott et al. (2008), enfatizam que além dos fertilizantes, variações no preço do petróleo também afeta os preços dos agroquímicos utilizados nas lavouras dos Estados Unidos e da China.

No Brasil, o milho e a soja são culturas de verão, portanto, substitutas na fase de cultivo. Contudo, são produtos complementares na fase de consumo, principalmente na composição de ração animal. Assim, espera-se que haja relações causais nos preços destas commodities à semelhança do que também já foi observado em outros países (Zhang et al. 2009; Shagaian, 2010; Nazlioglu e Soytas 2011)

Os trabalhos em economia agrícola no Brasil mostram que as cadeias estão integradas e que a estrutura de mercado em cada etapa da cadeia influencia na equidade da absorção dos choques de preços. O trabalho de Profeta \& Lima (2012) mostra claramente que a elasticidade de transmissão é desfavorável ao elo agricultor em comparação ao fornecedor de fertilizantes. Ademais, alguns estudos também mostram a existência de integração entre commodities (integração horizontal), como é o caso do milho e da soja, tanto nos mercados físicos, quanto futuros (Libera, 2009; Caldarelli e Bacchi, 2012). Há também evidências que alterações dos preços do milho são transferidas para a carne de frango (Almeida 2010; Caldarelli, 2013).

Portanto, o modelo desta pesquisa parte do insumo básico, o petróleo, sob a hipótese de que choques nos preços internacionais deste insumo são transferidos para os preços dos fertilizantes. Contudo, pelas razões apresentadas acima a expectativa é que não haja impactos do preço do petróleo nos preços dos grãos e da carne de frango. Ademais, pressupõe-se que o impacto das alterações do preço do petróleo nos preços dos grãos se dá via alterações dos preços dos fertilizantes. O estudo aqui proposto traz uma avaliação mais ampla das transmissões de preços no mercado brasileiro das commodities agrícolas. Como apresentado na seção introdutória o objetivo é construir um quadro ampliado das relações verticais e horizontais entre preços de importantes cadeias produtivas do agronegócio brasileiro.

\section{Métodos e Procedimentos}

A abordagem econométrica usada para testar as hipóteses do modelo proposto será a Análise de Autorregressão Vetorial (VAR), considerando as propriedades de integração e cointegração das séries temporais utilizadas. 
Uma vantagem de utilizar o modelo VAR é o reduzido grau de instruções teóricas sobre sua estrutura (Alves, 2002). Deve-se especificar as variáveis que vão interagir dentro do sistema e determinar o número de defasagens necessárias para captar a dinâmica de interação entre as variáveis do modelo. Entretanto, a ordem de entrada das variáveis do sistema deve ser estabelecida com base em conhecimentos teóricos.

Um modelo VAR estrutural com $\mathrm{p}$ defasagens e $n$ variáveis é dado por:

$$
B X_{t}=\Gamma_{0}+\Gamma_{1} X_{t-1}+\Gamma_{2} X_{t-2}+\cdots+\Gamma_{\mathrm{p}} X_{t-\mathrm{p}}+\varepsilon_{t}
$$

onde $B$ é a matriz $(n x n)$ de relações contemporâneas; $X_{t}$ é um vetor $(n x 1)$ com as variáveis incluídas no modelo VAR cujas inter-relações são analisadas; $\Gamma_{0}$ é um vetor $(n x 1)$ de termos de intercepto; $\Gamma_{\mathrm{i}}, i=1, \ldots, p$ são as matrizes $(n \times n)$ de coeficientes; $X_{t-i}, i=1, \ldots, p$ são os vetores $(n \times 1)$ com as variáveis defasadas incluídas no modelo VAR e $\varepsilon_{t}$ é um vetor $(n \times 1)$ de choques ortogonais cujos coeficientes são ruídos brancos não correlacionados.

reduzida:

Multiplicando a equação (1) por $B^{-1}$, obtém-se o modelo VAR na forma

$$
X_{t}=\mathrm{A}_{0}+\mathrm{A}_{1} X_{t-1}+\mathrm{A}_{2} X_{t-2}+\cdots+A_{p} X_{t-p}+\mathrm{e}_{t}
$$

onde $A_{0}=B^{-1} \Gamma_{0}, A_{j}=B^{-1} \Gamma_{\mathrm{i}}, i=1, \ldots, p$ e $e_{t}=B^{-1} \varepsilon_{\mathrm{t}}$.

O sistema é transformado da forma estrutural para a forma reduzida para que se possa estimar o modelo pelo Método de Mínimos Quadrados Ordinários. Assim, a identificação do modelo VAR está relacionada ao modo com que se recupera o modelo na forma estrutural a partir da forma reduzida.

Para a aplicação da metodologia VAR é necessário que as séries sejam todas estacionárias. Assim, o primeiro passo é verificar sua ordem de integração, ou seja, o número de raízes unitárias existentes.

Para testar a presença de raiz unitária optou-se pelo método desenvolvido por Elliott, Rothenberg e Stock (1996), conhecido como teste DF-GLS (Dickey Fuller Generalized Least Square), por ser mais robusto que o de Dickey-Fuller Aumentado quando o processo gerador da série apresenta média e tendência não observáveis, e se desenvolver satisfatoriamente em pequenas amostras, visto que o teste $\mathrm{ADF}$ foi desenvolvido para grandes amostras.

O número de defasagens, $p$, é determinado pelo Critério Modificado de Akaike (MAIC), desenvolvido por Ng e Perron (2001), visto que os tradicionais critérios de informação, AIC e SC, tendem a selecionar baixos valores para as defasagens quando se tem raízes unitárias negativas (próximas a -1), levando a conclusões distorcidas.

Caso as séries não sejam estacionárias, mas sejam todas integradas de mesma ordem, verifica-se a existência de cointegração entre elas e ajusta-se um modelo com a inclusão de termos de correção de erros (VEC), com as séries diferenciadas.

A cointegração é útil para indicar se existe uma relação de equilíbrio de longo prazo entre as variáveis. Um dos testes bastante utilizados para verificar a existência de vetores de cointegração é o teste de cointegração de Johansen (1988) que utiliza estimadores de máxima verossimilhança e permite testar a 
presença de múltiplos vetores de cointegração. Considerando n variáveis, o teste de cointegração de J ohansen pode ser descrito da seguinte forma:

$$
\Delta X_{t}=A_{0}+\Pi X_{t-1}+\psi D_{t}+\varepsilon_{t}
$$

em que $\Delta X_{t}=X_{t}-X_{t-1}, A_{0}$ e $\varepsilon_{t}$ são vetores $(n x 1), \Pi=\left(A_{1}-I\right)$ é uma matriz $(n x n), A_{1}$ é a matriz de parâmetros e I a matriz identidade, ambas ( $\left.n x n\right), \psi$ é uma matriz $(n x(f-1))$ e $D_{t}$ é um vetor de variáveis não estocásticas $((f-1) x 1)$.

O posto ou rank da matriz $\Pi$ corresponde ao número de raízes características diferentes de zero, que por sua vez, equivale ao número de vetores de cointegração existentes.

Para verificar o número de raízes características (r) diferentes de zero utiliza-sea estatística traço, como segue:

$$
\lambda_{\text {traço }}(r)=-T \sum_{i=r+1}^{n} \ln \left(1-\hat{\lambda}_{i}\right)
$$

onde $\hat{\lambda}_{i}$ são os valores estimados das raízes características obtidos da matriz П e T é o número de observações usadas no ajustamento.

Após determinar o posto de $\Pi$, que corresponde ao número de vetores de cointegração existentes, restringe-se essa matriz para construir o modelo de correção de erro.

Com base na equação (2), o modelo VEC pode ser descrito da seguinte forma:

$$
\Delta X_{t}=A_{0}+\Gamma_{1} \Delta X_{t-1}+\Gamma_{2} \Delta X_{t-2} \ldots+\Gamma_{p-1} \Delta X_{t-p+1}+\Pi X_{t-1}+\varepsilon_{t}
$$

A matriz $\Pi$ em (5) pode ser representada por: $\Pi=\alpha \beta^{\prime}$. Dessa forma, o termo de correção de erro é dado por:

$$
\Pi X_{t-1}=\alpha \beta^{\prime} X_{t-1}
$$

onde $\alpha$ é a velocidade de ajustamento dos parâmetros da matriz no curto prazo, $\beta^{\prime}$ é uma matriz de coeficientes de cointegração de longo prazo, $\beta^{\prime} X_{t-1}$ representa até $(n-1)$ relações de cointegração no modelo multivariado, assegurando assim que $X_{t}$ converge para uma solução de equilíbrio de longo prazo.

Conforme ressaltado por Bacchi (2007), a metodologia VAR permite decompor a variância dos erros de previsão $\mathrm{k}$ períodos à frente em percentuais a serem atribuídos a cada variável do sistema, por meio da qual é possível avaliar o poder explicativo de cada variável sobre as demais.

Considerando, como exemplo, um modelo VAR bivariado, a variância do erro de previsão, $\mathrm{n}$ períodos à frente, pode ser denotada por $\sigma_{x_{1}}(n)^{2}$ :

$$
\begin{aligned}
\sigma_{x_{1}}(n)^{2}= & \sigma_{x_{1}}^{2}\left[\phi_{11}(0)^{2}+\phi_{11}(1)^{2}+\cdots+\phi_{11}(n-1)^{2}\right]+ \\
& \sigma_{x_{2}}^{2}\left[\phi_{12}(0)^{2}+\phi_{12}(1)^{2}+\cdots+\phi_{12}(n-1)^{2}\right]
\end{aligned}
$$

A decomposição da variância do erro de previsão pode então ser representada por:

$$
\frac{\sigma_{x_{1}}^{2}\left[\phi_{11}(0)^{2}+\phi_{11}(1)^{2}+\cdots+\phi_{11}(n-1)^{2}\right]}{\sigma_{x_{1}}(n)^{2}}
$$




$$
\frac{\sigma_{x_{2}}^{2}\left[\phi_{12}(0)^{2}+\phi_{12}(1)^{2}+\cdots+\phi_{12}(n-1)^{2}\right]}{\sigma_{x_{1}}(n)^{2}}
$$

Essa decomposição indica a proporção do movimento de uma variável em função de um choque nela própria contra os choques em outras variáveis do sistema.

Bacchi (2007) enfatiza que a sequência $\left\{x_{1 t}\right\}$ será exógena se os choques $\varepsilon_{2 t}$ não explicarem nenhuma parcela da variância do erro de previsão de $\left\{x_{1 t}\right\}$ ao longo de todo o período previsto. Entretanto, se aqueles choques conseguirem explicar toda a variância do erro de previsão de $\left\{x_{1 t}\right\}$, esta sequência será endógena.

Segundo Alves (2002), outra possibilidade da utilização do modelo VAR está na obtenção do tempo de reação e da intensidade das respostas a choques sobre as variáveis, bem como da direção, padrão e duração dessas respostas. Este procedimento é conhecido como função de reposta a impulso.

De acordo com Enders (2015), a representação da função de resposta a impulso pode ser feita por meio de um vetor de médias móveis, onde as variáveis $x_{1 t} \mathrm{e}$ $x_{2 t}$ são expressas em termos dos valores presentes e passados dos erros $e_{1 t}$ e $e_{2 t}$. Desse modo, considerando o modelo bivariado, o modelo de média móvel é dado por:

$$
X_{t}=\mu+\sum_{i=0}^{\infty} A_{1}^{i} e_{t-i}
$$

onde $\mu=\left[\begin{array}{ll}\bar{x}_{1} & \bar{x}_{2}\end{array}\right]$

A representação da média móvel é utilizada para examinar as interações entre as variáveis $x_{1 t}$ e $x_{2 t}$.

Para verificar as relações de causalidade entre as variáveis foi utilizado o teste de causalidade de Granger (1969). A causalidade no sentido de Granger considera que há existência de causalidade de uma variável $\mathrm{X}$ para uma variável $\mathrm{Y}$ se, e somente se, valores passados (defasados) de $\mathrm{X}$ ajudam na previsão de Y. O teste baseia-se nas seguintes equações:

$$
\begin{aligned}
& Y_{t}=\alpha_{0}+\sum_{i=1}^{k} \propto_{1 i} X_{t-i}+\sum_{j=1}^{k} \alpha_{2 j} Y_{t-j}+\varepsilon_{1 t} \\
& X_{t}=\beta_{0}+\sum_{i=1}^{k} \beta_{1 i} Y_{t-i}+\sum_{j=1}^{k} \beta_{2 j} X_{t-j}+\varepsilon_{2 t}
\end{aligned}
$$

em que $\mathrm{k}$ é o número de defasagens usadas no modelo, $\alpha_{0}, \alpha_{1 \mathrm{i}}$ e $\alpha_{2 \mathrm{j}}$ são os parâmetros estimados na equação (11) e $\beta_{0}, \beta_{1 \mathrm{i}}$ e $\beta_{2 \mathrm{j}}$ são os parâmetros estimados na equação (12).

Supõe-se que os erros aleatórios $\varepsilon_{1 \mathrm{t}}$ e $\varepsilon_{2 \mathrm{t}}$ não tenham correlação. As hipóteses de nulidade testadas serão: $\alpha_{11}=\alpha_{12}=\ldots=\mathrm{a}_{1 \mathrm{n}}=0$ (na equação 11) e $\beta_{11}=\beta_{12}=\ldots=\beta_{1 \mathrm{n}}$ $=0$ (na equação 12).

Se as duas hipóteses forem rejeitadas, há a causalidade bidirecional; se ambas hipóteses não forem rejeitadas, há a ausência de causalidade; se a primeira hipótese for rejeitada e a segunda não, a causalidade será unidirecional de $\mathrm{X}_{\mathrm{t}}$ para $\mathrm{Y}_{\mathrm{t}} \mathrm{e}$, por fim, se a primeira hipótese não for rejeitada, mas a segunda for, a causalidade será unidirecional de $\mathrm{Y}_{\mathrm{t}}$ para $\mathrm{X}_{\mathrm{t}}$. 


\section{Fonte e Tratamentos dos Dados}

Para o desenvolvimento das análises foram utilizadas séries mensais de preços das commodities (frango, milho, soja e petróleo), dos fertilizantes minerais (superfostato simples, cloreto de potássio e sulfato de amônia) e da taxa de câmbio no período de janeiro de 2006 a dezembro de 2016. As fontes e as unidades de medida dessas séries são apresentadas no Quadro 1.

Todos os valores foram transformados em logaritmo, de modo que as relações entre as variáveis pudessem ser interpretadas como elasticidades. O preço internacional do petróleo foi transformado em reais. Além disso, todas as séries foram deflacionadas pelo IGP-DI, divulgado pela FGV.

Quadro 1. Detalhamento das variáveis empregadas.

\begin{tabular}{|l|c|c|c|}
\hline Variável & Descrição da variável & Unidade & Fonte \\
\hline $\begin{array}{l}\text { Frango } \\
\text { (Fg) }\end{array}$ & $\begin{array}{c}\text { Frango - preço do quilo do frango } \\
\text { resfriado no atacado }\end{array}$ & $\mathrm{R} \$ /$ quilo & $\mathrm{IPEA}^{1}$ \\
\hline Milho (M) & Milho - preço pago ao produtor & $\mathrm{R} \$ /$ saca de 60 & $\mathrm{IPEA}^{1}$ \\
\hline Soja (Sj) & Soja - preço pago ao produtor & $\mathrm{R} \$ /$ saca de 60 & $\mathrm{IPEA}^{1}$ \\
\hline $\begin{array}{l}\text { Cloreto de } \\
\text { Potássio } \\
\text { (CP) }\end{array}$ & $\begin{array}{c}\text { Cloreto de Potássio - preço pago pelo } \\
\text { produtor }\end{array}$ & $\mathrm{R} \$ /$ tonelada & $\mathrm{IEA}^{2}$ \\
\hline $\begin{array}{l}\text { Superfosfato } \\
\text { Simples } \\
\text { (SFS) }\end{array}$ & $\begin{array}{c}\text { Superfosfato Simples - preço pago pelo } \\
\text { produtor }\end{array}$ & $\mathrm{R} \$ /$ tonelada & $\mathrm{IEA}^{2}$ \\
\hline $\begin{array}{l}\text { Sulfato de } \\
\text { Amônia } \\
\text { (AS) }\end{array}$ & $\begin{array}{c}\text { Sulfato de Amônia - preço pago pelo } \\
\text { produtor }\end{array}$ & $\mathrm{R} \$ /$ tonelada & $\mathrm{IEA}^{2}$ \\
\hline Petróleo & Preço mundial do petróleo & & \\
\hline Câmbio (Cb) & Taxa de câmbio comercial de venda & $\mathrm{R} \$ /$ Barril & FM" $^{1}$ \\
\hline
\end{tabular}

${ }^{1}$ Instituto de Pesquisa Econômica Aplicada; ${ }^{2}$ Instituto de Economia Agrícola; ${ }^{3}$ Fundo Monetário Internacional.

\section{Resultados}

Os resultados dos testes de raiz unitária são apresentados, para os dois modelos testados, na Tabela 1, o modelo A considerou constante e tendência e o modelo B constante apenas. O número de defasagens, determinado pelo Critério de Informação de Akaike Modificado (MAIC), para cada modelo, está apresentado na segunda e quarta colunas da Tabela 1. 
Tabela 1. Resultados dos testes de raiz unitária de Elliott-Rothenberg-Stock (DFGLS).

\begin{tabular}{|c|c|c|c|c|}
\hline \multirow[b]{2}{*}{ Variável } & \multicolumn{2}{|r|}{ Modelo A } & \multicolumn{2}{|r|}{ Modelo B } \\
\hline & $\mathrm{p}$ & $\begin{array}{l}\text { Estatística DF- } \\
\text { GLS }\end{array}$ & $\mathrm{p}$ & $\begin{array}{l}\text { Estatística DF- } \\
\text { GLS }\end{array}$ \\
\hline Frango & 8 & $-2,713$ & 0 & $-2,209$ \\
\hline Milho & 2 & $-2,524$ & 0 & $-1,756$ \\
\hline Soja & 2 & $-2,679$ & 0 & $-1,120$ \\
\hline Cloreto de Potássio & 0 & $-1,649$ & 0 & -0.676 \\
\hline Superfosfato simples & 0 & $-1,300$ & 0 & -0.847 \\
\hline Sulfato de amônia & 1 & $-2,112$ & 0 & $-1,563$ \\
\hline Petróleo & 1 & $-2,925$ & 0 & $-1,400$ \\
\hline Câmbio & 1 & $-1,396$ & 0 & $-0,615$ \\
\hline
\end{tabular}

Fonte: Resultados da pesquisa.

Nota: Modelo A: na versão com constante e tendência (valores críticos em Elliott, Rothenberg e Stock (1996) $(5 \%=-2,93,1 \%=-3,46))$; Modelo B: na versão apenas com constante (valores críticos em Dickey e Fuller $(1979 ; 1981)(5 \%=-1,95$ e $1 \%=-2,58))$.

Cientes de que todas as séries são integradas de mesma ordem, o passo seguinte foi a verificação de cointegração das séries utilizando o teste de cointegração de J ohansen. Os critérios de AIC e SC, recomendam um modelo com apenas uma defasagem. A estatística traço e os respectivos valores críticos determinam que existem dois vetores de cointegração entre as séries do modelo, conforme pode ser visto na Tabela 2.

Tabela 2. Resultados dos testes de cointegração de J ohansen entre as séries.

\begin{tabular}{ccccc}
\hline $\begin{array}{c}\text { Hipótese } \\
\text { Nula }\end{array}$ & $\begin{array}{c}\text { Hipótese } \\
\text { Alternativa }\end{array}$ & $\begin{array}{c}\text { Estatística } \\
\text { Traço }\end{array}$ & $\begin{array}{c}\text { Valores } \\
\text { Críticos* }\end{array}$ & P-Valor \\
\hline $\mathrm{r}=0$ & $\mathrm{r}>0$ & 194,062 & 159,319 & $0,000^{*}$ \\
$\mathrm{r} \leq 1$ & $\mathrm{r}>1$ & 138,776 & 125,417 & $0,005^{*}$ \\
$\mathbf{r} \leq \mathbf{2}$ & $\mathrm{r}>2$ & 93,882 & 95,514 & 0,065 \\
$\mathrm{r} \leq 3$ & $\mathrm{r}>3$ & 58,837 & 69,611 & 0,274 \\
$\mathrm{r} \leq 4$ & $\mathrm{r}>4$ & 25,495 & 47,707 & 0,901 \\
$\mathrm{r} \leq 5$ & $\mathrm{r}>5$ & 15,048 & 29,804 & 0,780 \\
$\mathrm{r} \leq 6$ & $\mathrm{r}>6$ & 7,258 & 15,408 & 0,554 \\
$\mathrm{r} \leq 7$ & $\mathrm{r}>7$ & 1,869 & 3,841 & 0,172 \\
\hline
\end{tabular}

Fonte: Resultados da pesquisa.

*Significativo a 5\% (valores críticos em Osterwald-Lenum (1992). Modelo ajustado com drift, com constante fora do espaço de cointegração. 
Pelo resultado do teste de causalidade de Granger é possível concluir que para o mercado brasileiro há fraca relação entre as séries de preço de commodities agrícolas e energéticas, pois como se observa na Tabela 3, o petróleo foi significativo apenas para o preço do frango, sem causalidade em relação ao preço dos grãos. Resultado semelhantefoi encontrado em relação aos fertilizantes, onde se observa a ausência de causalidade no sentido de Granger do petróleo para os três fertilizantes básicos.

Ao analisar a dependência entre as séries de preços de fertilizantes e grãos - que apresentam uma relação direta de insumo e produto - nota-se que o preço do milho é causado no sentido de Granger pelo preço de dois fertilizantes (CP e SA), enquanto o preço da soja não sofre influência dos preços dos fertilizantes básicos (Tabela 3). Por outro lado, a soja causa no sentido de Granger o preço do cloreto de potássio e do superfosfato simples. O milho, por sua vez, causa o preço do superfostato simples. Ademais, a relação de complementariedade entre os fertilizantes básicos fica evidente diante da causalidade no sentido de Granger existente entre esses produtos.

Tabela 3. Teste de causalidade de Granger.

\begin{tabular}{|c|c|c|c|c|c|c|c|c|}
\hline \multirow{2}{*}{$\begin{array}{l}\text { Variável } \\
\text { explicativa }\end{array}$} & \multicolumn{8}{|c|}{ Variável dependente } \\
\hline & $\mathrm{Fg}$ & $\mathrm{Ml}$ & $\mathrm{Sj}$ & $\mathrm{CP}$ & SFS & & Ptr & $\mathrm{Cb}$ \\
\hline $\mathrm{Fg}$ & $139,54^{*}$ & 23,89 & 11,66 & 0,11 & 0,31 & 0,05 & 13,47 & 22,80 \\
\hline M & 0,06 & $83,50 *$ & 0,32 & 0,01 & $30,1^{*}$ & 0,74 & 0,092 & 14,87 \\
\hline $\mathrm{Sj}$ & 0,22 & 0,141 & $141^{*}$ & $58,5^{*}$ & $69,3^{*}$ & 17,65 & 0,021 & 0,001 \\
\hline $\mathrm{CP}$ & 23,30 & $47,20^{*}$ & 0,01 & 0,00 & 10,8 & $84,5^{*}$ & 13,48 & 0,016 \\
\hline SFS & 15,56 & 0,09 & 0,19 & $28,6^{*}$ & $10,6^{*}$ & $85,8^{*}$ & 0,259 & 0,279 \\
\hline AS & 0,002 & $53,83^{*}$ & 0,00 & 15,40 & 36,83 & 24,69 & 0,508 & 0,470 \\
\hline Ptr & $30,11 *$ & 0,62 & 0,00 & 0,59 & 0,40 & 23,55 & $83,3 *$ & 0,197 \\
\hline $\mathrm{Cb}$ & 14,09 & 0,05 & 0,01 & 0,09 & 0,02 & $55,2^{*}$ & $38,2^{*}$ & $187,7 *$ \\
\hline
\end{tabular}

Fonte: Resultados da pesquisa.

Nota: Os valores reportados na Tabela referem-se ao valor do teste F.

Apesar da alta taxa de importação e exportação de alguns produtos a taxa de câmbio causa no sentido de Granger apenas o preço do sulfato de amônia e do petróleo.

As Tabelas 4 a 9 apresentam as variâncias dos erros de previsão, de cada variável utilizada na análise, decompostas 10 meses à frente. Esses resultados reforçam os obtidos no teste de causalidade de Granger. Para a maioria das variáveis, um baixo percentual da variância do erro de previsão é explicado pelas outras variáveis, sendo o choque no próprio preço o responsável por explicar o maior percentual da variância, no curto prazo. No caso do frango (Tabela 4) se observa que, além de um choque no próprio preço, o milho é a variável que mais explica a variância do erro de previsão. Essa relação era esperada, e reforça a relação 
entre produto einsumo, uma vezque o milho éo principal insumo na alimentação do frango.

Tabela 4. Decomposição da variância do erro de previsão do frango.

\begin{tabular}{cccccccccc}
\hline Mês & d.p. & Fg & Ml & Sj & CP & SFS & AS & Ptr & Cb \\
\hline 1 & 0,044 & 96,318 & 3,390 & 0,011 & 0,014 & 0,062 & 0,039 & 0,167 & 0,000 \\
2 & 0,048 & 88,82 & 3,388 & 0,292 & 1,844 & 1,325 & 0,034 & 3,487 & 0,806 \\
3 & 0,049 & 86,69 & 3,297 & 0,366 & 1,875 & 1,784 & 0,053 & 4,458 & 1,476 \\
4 & 0,049 & 86,175 & 3,279 & 0,416 & 1,879 & 1,862 & 0,054 & 4,615 & 1,721 \\
5 & 0,049 & 86,07 & 3,276 & 0,433 & 1,877 & 1,871 & 0,054 & 4,634 & 1,782 \\
6 & 0,049 & 86,05 & 3,276 & 0,438 & 1,877 & 1,872 & 0,054 & 4,635 & 1,794 \\
7 & 0,049 & 86,05 & 3,276 & 0,439 & 1,877 & 1,872 & 0,054 & 4,635 & 1,796 \\
8 & 0,049 & 86,05 & 3,276 & 0,440 & 1,877 & 1,872 & 0,054 & 4,635 & 1,796 \\
9 & 0,049 & 86,05 & 3,276 & 0,440 & 1,877 & 1,872 & 0,054 & 4,635 & 1,796 \\
10 & 0,049 & 86,05 & 3,276 & 0,440 & 1,877 & 1,872 & 0,054 & 4,635 & 1,796 \\
\hline
\end{tabular}

Fonte: Resultados da pesquisa.

Um choque no preço da soja explica em torno de um quarto da variância do erro de previsão do milho (Tabela 5). Esse resultado reforça a hipótese que o preço do milho depende do comportamento de preço da soja, visto que ambos são substitutos no cultivo de verão, e normalmente, a área plantada com cada um dos dois cultivos depende mais do preço da soja do que preço do milho. Em outras palavras, o produtor se referencia no preço da soja para tomar a decisão pelo plantio, ou não, do milho.

Tabela 5. Decomposição da variância do erro de previsão do milho.

\begin{tabular}{cccccccccc}
\hline Mês & d.p. & Fg & M & Sj & CP & SFS & AS & Ptr & Cb \\
\hline 1 & 0,060 & 0,000 & 70,02 & 25,93 & 0,121 & 0,849 & 0,948 & 2,129 & 0,000 \\
2 & 0,067 & 1,290 & 62,46 & 23,755 & 4,156 & 0,992 & 5,490 & 1,818 & 0,032 \\
3 & 0,068 & 1,780 & 61,497 & 23,764 & 4,083 & 1,037 & 5,851 & 1,919 & 0,069 \\
4 & 0,068 & 1,987 & 61,188 & 23,678 & 4,112 & 1,159 & 5,847 & 1,924 & 0,105 \\
5 & 0,068 & 2,042 & 61,105 & 23,652 & 4,132 & 1,197 & 5,840 & 1,922 & 0,111 \\
6 & 0,068 & 2,052 & 61,089 & 23,646 & 4,135 & 1,204 & 5,840 & 1,924 & 0,111 \\
7 & 0,068 & 2,052 & 61,085 & 23,645 & 4,135 & 1,204 & 5,841 & 1,925 & 0,111 \\
8 & 0,068 & 2,052 & 61,084 & 23,645 & 4,135 & 1,204 & 5,841 & 1,926 & 0,112 \\
9 & 0,068 & 2,052 & 61,084 & 23,645 & 4,135 & 1,204 & 5,841 & 1,926 & 0,112 \\
10 & 0,068 & 2,052 & 61,084 & 23,645 & 4,135 & 1,204 & 5,841 & 1,926 & 0,112
\end{tabular}

Fonte: Resultados da pesquisa. 
No caso da soja, a decomposição da variância do erro de previsão corrobora com o teste de causalidade de Granger, no sentido de ter um comportamento fortemente exógeno, dependente basicamente do próprio preço (Tabela 6).

Tabela 6. Decomposição da variância do erro de previsão da soja.

\begin{tabular}{cccccccccc}
\hline Mês & d.p. & Fg & M & Sj & CP & SFS & AS & Ptr & Cb \\
\hline 1 & 0,046 & 0,000 & 0,000 & 97,744 & 0,110 & 0,140 & 0,021 & 1,986 & 0,000 \\
2 & 0,049 & 0,692 & 0,090 & 96,68 & 0,098 & 0,488 & 0,022 & 1,918 & 0,012 \\
3 & 0,05 & 0,936 & 0,144 & 96,016 & 0,180 & 0,629 & 0,083 & 1,975 & 0,038 \\
4 & 0,05 & 0,983 & 0,161 & 95,792 & 0,193 & 0,663 & 0,105 & 2,032 & 0,071 \\
5 & 0,05 & 0,987 & 0,165 & 95,730 & 0,194 & 0,668 & 0,109 & 2,055 & 0,093 \\
6 & 0,05 & 0,987 & 0,165 & 95,714 & 0,194 & 0,668 & 0,110 & 2,061 & 0,101 \\
7 & 0,05 & 0,987 & 0,165 & 95,710 & 0,194 & 0,668 & 0,110 & 2,062 & 0,104 \\
8 & 0,05 & 0,987 & 0,165 & 95,710 & 0,194 & 0,668 & 0,110 & 2,062 & 0,104 \\
9 & 0,05 & 0,987 & 0,165 & 95,710 & 0,194 & 0,668 & 0,110 & 2,062 & 0,104 \\
10 & 0,05 & 0,987 & 0,165 & 95,710 & 0,194 & 0,668 & 0,110 & 2,062 & 0,104 \\
\hline
\end{tabular}

Fonte: Resultados da pesquisa.

A despeito da baixa causalidade no sentido de Granger do petróleo em relação às commodities agrícolas, a dependência entre esses produtos fica mais evidente na decomposição da variância do erro de previsão. Embora nos primeiros períodos a própria variável explique a maior parte da variância do erro de previsão, o petróleo aparece como uma das variáveis mais importantes para as três commodities agrícolas: frango, milho e soja. Apesar de presente, nota-se que o percentual de explicação é modesto.

Novamente é possível observar a relação de dependência entre os preços dos grãos e os preços dos fertilizantes básicos (Tabelas 5 e 6). O CP e o SA explicam uma parcela da variância do erro de previsão do milho (Tabela 5). Em contrapartida a soja explica uma parcela da variância do erro de previsão do CP (Tabela 7), assim como o milho e soja explicam uma parcela da variância do erro de previsão do SFS e do SA (Tabelas 8 e 9).

A relação de dependência entre os três fertilizantes básicos é novamente evidenciada, pois além do próprio preço, os demais fertilizantes também explicam uma parcela da variância do erro de previsão (Tabelas 7, 8 e 9). Esse resultado se origina da complementariedade dos três produtos, onde a maior parte do volume comercializado ocorre por meio de formulações que contêm os três produtos em diferentes combinações. 
Tabela 7. Decomposição da variância do erro de previsão do CP.

\begin{tabular}{cccccccccc}
\hline Mês & d.p. & Fg & Ml & Sj & CP & SFS & AS & Ptr & Cb \\
\hline 1 & 0,05 & 0,000 & 0,000 & 0,000 & 99,92 & 0,000 & 0,000 & 0,078 & 0,000 \\
2 & 0,05 & 0,071 & 0,001 & 5,575 & 90,37 & 2,602 & 1,071 & 0,243 & 0,058 \\
3 & 0,05 & 0,076 & 0,087 & 6,027 & 89,65 & 2,736 & 1,085 & 0,251 & 0,083 \\
4 & 0,05 & 0,080 & 0,106 & 6,109 & 89,531 & 2,737 & 1,099 & 0,251 & 0,087 \\
5 & 0,05 & 0,083 & 0,108 & 6,118 & 89,513 & 2,737 & 1,102 & 0,251 & 0,087 \\
6 & 0,05 & 0,084 & 0,108 & 6,120 & 89,510 & 2,738 & 1,102 & 0,251 & 0,087 \\
7 & 0,05 & 0,084 & 0,108 & 6,120 & 89,510 & 2,739 & 1,102 & 0,251 & 0,087 \\
8 & 0,05 & 0,084 & 0,108 & 6,120 & 89,50 & 2,739 & 1,102 & 0,251 & 0,087 \\
9 & 0,05 & 0,084 & 0,108 & 6,120 & 89,50 & 2,739 & 1,102 & 0,251 & 0,087 \\
10 & 0,05 & 0,084 & 0,108 & 6,120 & 89,50 & 2,739 & 1,102 & 0,251 & 0,087 \\
\hline
\end{tabular}

Fonte: Resultados da pesquisa.

Tabela 8. Decomposição da variância do erro de previsão do SFS.

\begin{tabular}{cccccccccc}
\hline Mês & d.p & Fg & Ml & Sj & CP & SFS & AS & Ptr & Cb \\
\hline 1 & 0,05 & 0,000 & 0,000 & 0,000 & 0,000 & 99,783 & 0,000 & 0,217 & 0,000 \\
2 & 0,062 & 0,191 & 1,754 & 2,679 & 1,235 & 90,70 & 3,123 & 0,299 & 0,017 \\
3 & 0,062 & 0,239 & 1,963 & 3,302 & 1,235 & 89,09 & 3,621 & 0,439 & 0,108 \\
4 & 0,062 & 0,238 & 1,973 & 3,467 & 1,232 & 88,69 & 3,650 & 0,540 & 0,203 \\
5 & 0,062 & 0,240 & 1,971 & 3,506 & 1,235 & 88,59 & 3,647 & 0,563 & 0,243 \\
6 & 0,062 & 0,241 & 1,971 & 3,514 & 1,236 & 88,575 & 3,646 & 0,565 & 0,252 \\
7 & 0,062 & 0,242 & 1,971 & 3,515 & 1,236 & 88,572 & 3,646 & 0,566 & 0,253 \\
8 & 0,062 & 0,242 & 1,971 & 3,515 & 1,236 & 88,572 & 3,646 & 0,566 & 0,254 \\
9 & 0,062 & 0,242 & 1,971 & 3,515 & 1,236 & 88,572 & 3,646 & 0,566 & 0,254 \\
10 & 0,062 & 0,242 & 1,971 & 3,515 & 1,236 & 88,572 & 3,646 & 0,566 & 0,254 \\
\hline
\end{tabular}

Fonte: Resultados da pesquisa.

A decomposição da variância do erro de previsão do petróleo e da taxa de câmbio mostra que ambas as variáveis apresentam um comportamento fortemente exógeno e mesmo após 10 períodos à frente mais de $90 \%$ da variância do erro de previsão é explicado por um choque na própria variável. Como esperado o comportamento dessas duas variáveis independe dos preços das commodities agrícolas e dos fertilizantes básicos. Por outro lado, surpreendea baixa relevância da taxa de câmbio sobre a variância do erro de previsão, mesmo para produtos com alta taxa de importação, como os CP e SA ou exportação, como o frango e a soja. 
Tabela 9. Decomposição da variância do erro de previsão do AS.

\begin{tabular}{cccccccccc}
\hline Mês & d.p. & Fg & Ml & Sj & CP & SFS & AS & Ptr & Cb \\
\hline 1 & 0,035 & 0,000 & 0,000 & 0,000 & 0,000 & 0,000 & 99,92 & 0,078 & 0,000 \\
2 & 0,04 & 0,030 & 0,383 & 2,461 & 6,286 & 7,498 & 78,425 & 2,013 & 2,903 \\
3 & 0,041 & 0,183 & 0,850 & 3,323 & 6,921 & 8,349 & 74,249 & 2,245 & 3,880 \\
4 & 0,041 & 0,224 & 0,997 & 3,448 & 6,982 & 8,335 & 73,794 & 2,226 & 3,993 \\
5 & 0,041 & 0,226 & 1,019 & 3,460 & 6,978 & 8,326 & 73,762 & 2,237 & 3,992 \\
6 & 0,041 & 0,227 & 1,021 & 3,461 & 6,977 & 8,327 & 73,752 & 2,243 & 3,993 \\
7 & 0,041 & 0,227 & 1,021 & 3,460 & 6,977 & 8,328 & 73,749 & 2,243 & 3,994 \\
8 & 0,041 & 0,228 & 1,021 & 3,460 & 6,978 & 8,328 & 73,748 & 2,243 & 3,994 \\
9 & 0,041 & 0,228 & 1,021 & 3,460 & 6,978 & 8,328 & 73,748 & 2,243 & 3,994 \\
10 & 0,041 & 0,228 & 1,021 & 3,460 & 6,978 & 8,328 & 73,748 & 2,243 & 3,994
\end{tabular}

Fonte: Resultados da pesquisa.

As Figuras 2 a 5 mostram as respostas a impulsos nas variáveis analisadas nos doze períodos seguintes ao instante do choque inicial e avaliam como as séries de preços respondem a um choque no próprio preço eno preço dos demais produtos.

Na Figura 2 são apresentadas as funções impulso-resposta do frango e do milho e novamente a relação entre essas duas séries é confirmada: o preço do frango reage positivamente a um choque no preço do milho e vice e versa. Tal resultado revela que não apenas o choque no preço do milho é repassado para o preço do frango, mas também o aumento do preço do frango pode ser transmitido para o preço do milho, um dos seus principais destinos de processamento, nesse caso o efeito ocorre a partir do segundo mês.

Variações no preço do frango também afetam positivamente o preço da soja, mas esse efeito é menor ainda, cerca de $0,2 \%$. Com relação às outras variáveis analisadas o efeito é praticamente nulo.

A Figura 3(A) revela uma reação positiva do preço do milho frente a um choque exógeno no preço da soja. Um aumento de $1 \%$ no preço da soja leva a um aumento de cerca de $0,7 \%$ no preço do milho no primeiro mês, com transmissão mais do que proporcional a partir do terceiro mês. 


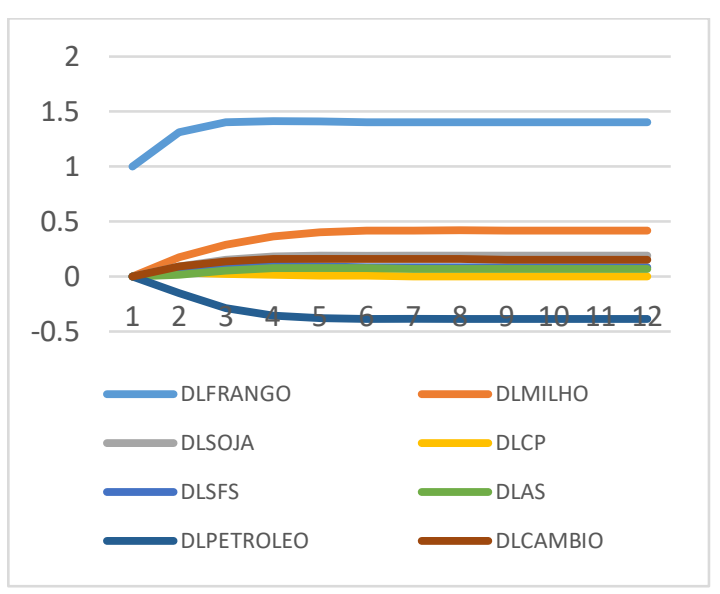

A

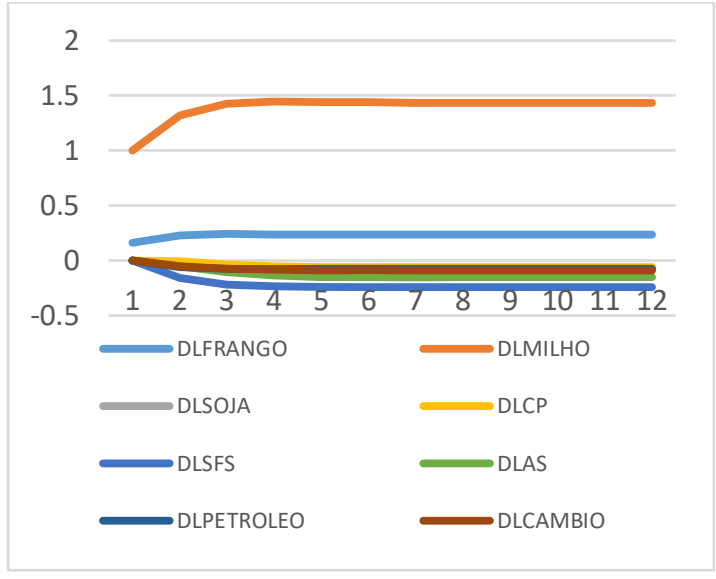

B

Figura 2. Respostas das variáveis analisadas a um choque não antecipado no preço do frango (A) e do milho (B).

O impacto de um choque exógeno no preço da soja sobre o preço do superfosfato simples também é positivo, porém menor, menos de $0,5 \%$ ao longo de todo o período subsequente ao choque inicial. Já os preços do cloreto de potássio e do sulfato de amônia reagem de forma negativa a variações no preço da soja, não ultrapassando $-0,5 \%$ nos doze meses seguintes.

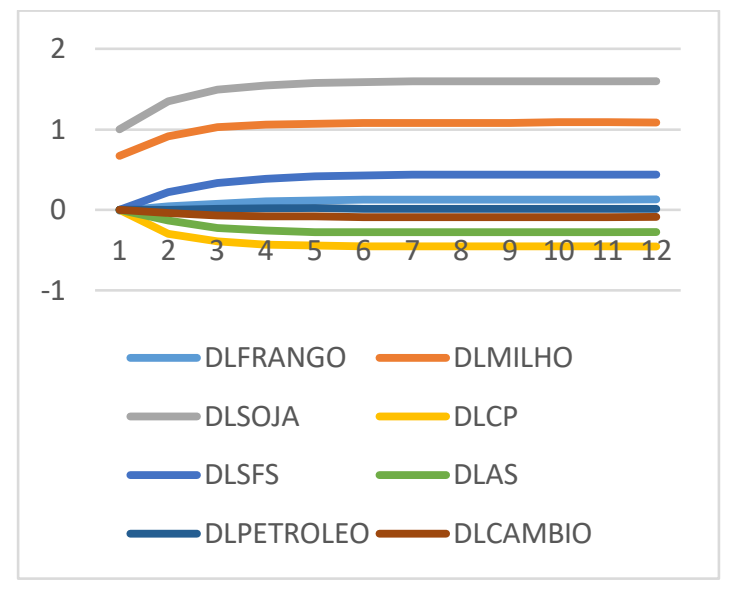

A

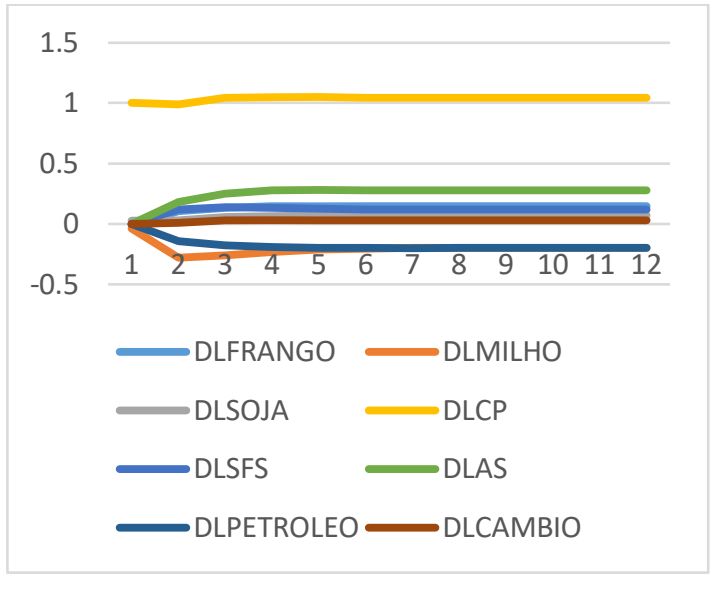

B

Figura 3. Respostas das variáveis analisadas a um choque não antecipado no preģo da soja (A) e do cloreto de potássio (B).

As Figuras 3(B) e 4 apresentam as funções impulso resposta para os três fertilizantes básicos, e a relação de dependência entre esses produtos é novamente explicitada. Observa-se na Figura 3(B) que o preço do sulfato de amônia reage positivamente, porém, com pouca intensidade a um choque não antecipado no preço do cloreto de potássio a partir do segundo mês, assim como os preços do superfostato simples e do frango. Os resultados mostram que assim como o choque no preço do milho e da soja é repassado para o preço dos fertilizantes básicos, os preços do milho e da soja também podem variar devido ao aumento de preço dos fertilizantes.

Conforme observado na Figura 4A, um choquenão antecipado no preço do superfosfato simples impacta de forma positiva, a partir do segundo mês, os 
preços do sulfato de amônia, do cloreto de potássio, do frango e da soja, embora esses efeitos sejam pequenos, em torno de $0,3 \%$ ao longo dos doze meses subsequentes ao choque inicial. O preço do milho sofre um pequeno efeito negativo nos três períodos iniciais, inferior a $0,2 \%$, impacto esse que se torna praticamente nulo a partir do quarto mês.

No entanto, um aumento de $1 \%$ no preço do sulfato de amônia leva a um aumento de mais de $0,7 \%$ no preço do milho a partir do terceiro mês (Figura 4B), resultado esse justificado pela alta dependência de nitrogênio (sulfato de amônia) na produção de milho.

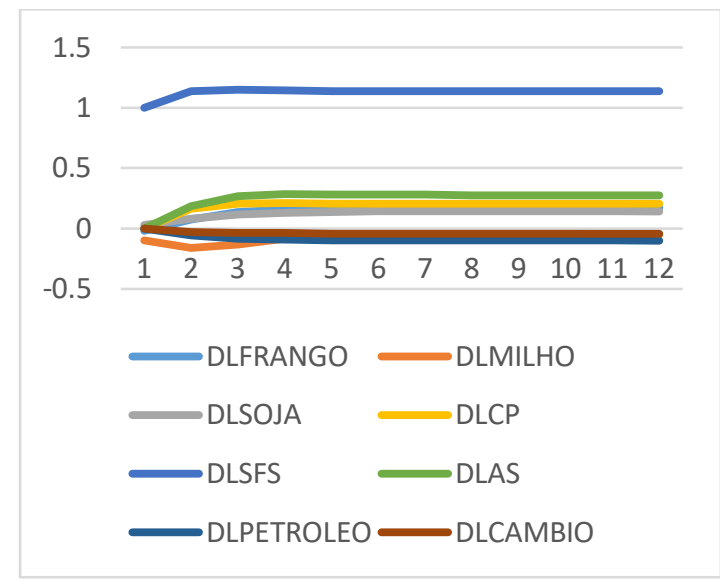

A

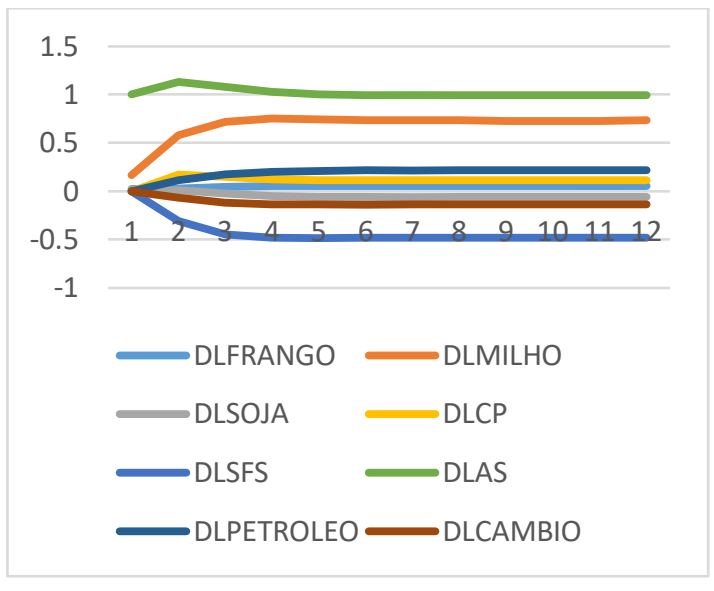

B

Figura 4. Respostas das variáveis analisadas a um choque não antecipado no preço do superfosfato simples (A) e do sulfato de amônia (B).

A influência do preço do petróleo sobre as variações é pouco expressiva: um aumento de $1 \%$ no preço do petróleo leva a uma variação menor que $0,25 \%$ no preço de todos os demais produtos, até mesmo para os fertilizantes básicos onde se esperava quea transmissão fossemais intensa, sendo esse efeito negativo sobre o sulfato de amônia (Figura 5).

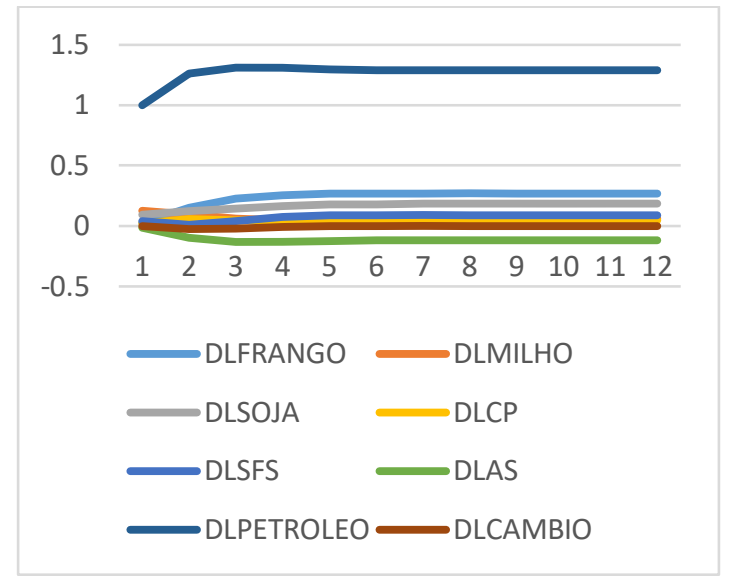

A

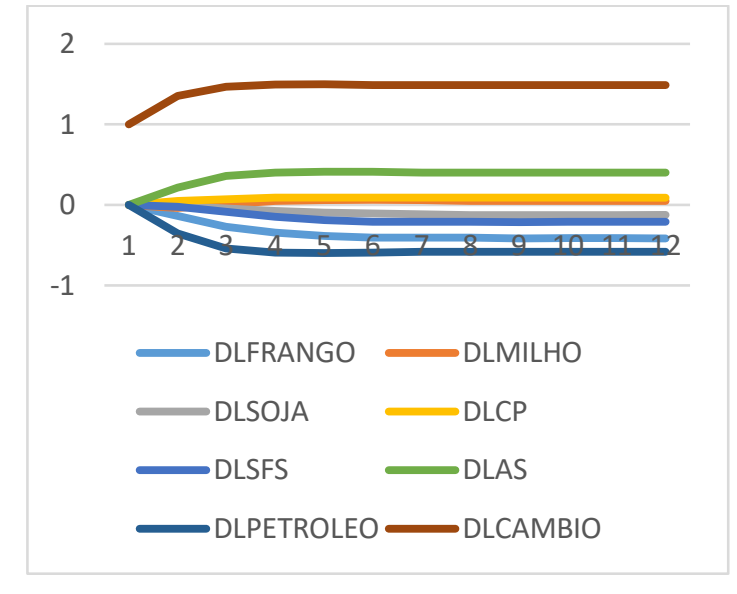

B

Figura 5. Respostas das variáveis analisadas a um choque não antecipado no preço do petróleo (A) e câmbio (B). 


\section{Discussão e considerações finais}

Conforme pressuposto na segunda seção deste artigo se observa que a relação do preço mundial do petróleo para os preços internos do milho e da soja no Brasil é pouco expressiva e quando presente possui um fraco impacto. Esses resultados estão em consonância com os estudos internacionais realizados na China (Zhang \& Reed2008) e na Turquia (Nazlioglu \& Soytas, 2011), mas são antagônicos aos encontrados por Reboredo (2012) para os Estados Unidos, onde a transmissão é observada especialmente nos anos recentes. Assim, pode-se dizer que o Brasil é mais parecido com o resto do mundo do que com os Estados Unidos. Como apresentado na seção 2 deste artigo, diferentemente dos Estados Unidos, onde esta ligação é dada pelo etanol produzido a partir do milho, no Brasil, esta relação não é tão direta, visto que o etanol é oriundo da cana.

Naquele país, os incentivos à produção de etanol à base de milho, a partir de meados da década passada (Avalos, 2014), alterou sobremaneira a dinâmica de preços das demais commodities, como da soja, trigo e algodão. No Brasil, este fenômeno foi menos intenso especialmente porque a expansão da produção do etanol se deu a partir da cana que ocupou principalmente áreas de pastagens, na região sudeste do país, distantes das principais regiões produtoras de grãos. Ademais, o programa de etanol a base de massa vegetal no Brasil é mais antigo que o americano. Assim, já havia uma cadeia de produção estruturada, de forma que, mesmo com os incentivos, os impactos não foram tão intensos a ponto de causar efeitos semelhantes ao programa americano, integrando-se o preço das commodities agrícolas ao do petróleo.

De maneira geral os resultados dos testes empregados nessa pesquisa sugerem uma dependência do preço do milho em relação ao preço da soja, que pode ser justificado, pelo menos parcialmente, pelo fato de que a soja tem sido a cultura preferida pelos agricultores, ao longo dos últimos anos. Alguns motivos para isso são o menor risco de perdas devido às secas, o menor custo de produção em relação ao milho e, principalmente, pela maior estabilidade de preços desta commodity. A exportação de aproximadamente $40 \%$ do total da produção nacional (FAO 2016), com preços relativamente altos no mercado internacional, estimula a expansão da área cultivada com soja e reduz a oferta de milho de primeira safra. Assim, a produção de milho tem se concentrado principalmente na safrinha ( $2^{\mathrm{a}}$ safra), após o cultivo da soja, ou na rotação de cultura.

Por outro lado, a exogeneidade do preço da soja em relação às demais variáveis do modelo, se deve, muito provavelmente, a forte dependência do preço interno ao mercado externo. Atualmente, o preço da saca de soja no mercado doméstico, tem como referência as bolsas americanas, especialmente a Bolsa de Chicago e Nasdaq, onde a formação depende mais dos aspectos de oferta e demanda mundial do que dos insumos ou produtos substitutos e complementares. Nesse caso, no entanto, surpreendea baixa significância da taxa de câmbio sobre o preço da soja.

Em relação à transmissão entre o preço do petróleo e dos fertilizantes básicos os resultados mostram ausência de transmissão neste elo da cadeia, o que refuta a hipótese inicial de que os impactos das alterações do preço do petróleo nos preços dos grãos dar-se-ia via a transmissão das alterações dos preços dos fertilizantes nos preços agrícolas. Quanto à transmissão grãos-fertilizantes, os resultados 
sugerem que elas ocorrem em ambas as direções, contudo de forma mais intensa dos grãos para os fertilizantes básicos, o que está em consonância com as premissas clássicas da estrutura de concorrência perfeita no mercado agrícola e de oligopsônio na indústria compradora dos grãos.

O preço da carne de frango apresenta certa dependência do preço do milho e uma fraca relação com o preço do petróleo. Em condições gerais, espera-se que um aumento no preço do milho seja repassado para o preço do frango, principalmente por ser um dos principais fatores dos custos de produção do frango. Por outro lado, por questões de concentração do mercado, um aumento no preço da carne de frango é fracamente repassado para o preço do milho, mesmo que a produção de ração para frango de corte seja um dos principais destinos do milho nacional. Contudo, fatos recentes demonstram certa rigidez desse mercado. Como observado ao longo do ano de 2016, quando o forte aumento no preço do milho não foi repassado para o preço do frango que, forçado por fatores econômicos como a demanda interna e a taxa de câmbio, seguiu tendência contrária e teve o preço reduzido.

De maneira geral se observa que as transmissões se concentram nos elos diretamente ligados: grãos e fertilizantes, milho e carne de frango e soja e milho, sendo menos intensos nos elos mais distantes, o que limite o efeito do petróleo sobre as commodities agrícolas.

\section{Referências}

ABBOTT, P. C.; HURT, C.; TYNER, W. E. What's Driving Food Prices?: Farm Foundation, 2008.

ABPA. Relatório Annual, 2016. Disponível em: http:// abpabr.com.br/ setores/ avicultura/ publicacoes/relatorios-anuais/2016. Acesso em 31 mai. de 2017.

ALMEIDA, F. P. Causalidade e transmissão de preços na cadeia avícola no período de 1997-2008. Dissertação (Mestrado em Agronomia) - Programa de Pós-Graduação em Agronomia, Universidade Federal de Uberlândia, 2010.

ALVES, L.R.A. Transmissão de preços entre produtos do setor sucroalcooleiro do estado de São Paulo. 2002. 107 p. Dissertação (Mestrado em Economia Aplicada) - Escola Superior de Agricultura "Luiz de Queiroz", Universidade de São Paulo, Piracicaba, 2002.

ARSHAD, F. M.; HAMEED, A. A. A. The long run relationship between petroleum and cereals prices. Global Economy \& Finance J ournal,v. 2, 2009.

AVALOS, F. Do oil prices drive food prices? The tale of a structural break. J ournal of International Money and Finance, v. 42, p. 253-271, Apr 2014. ISSN 0261-5606; 1873-0639.

BACCHI, M.R.P. Interdependência dos mercados de gasolina C e de álcool combustível no Estado de São Paulo. Tese (Livre-Docência) - Escola Superior de Agricultura “Luiz de Queiroz”, Universidade de São Paulo, Piracicaba, 2007. 
BAFFES, J . Oil spills on other commodities. Resources Policy, v. 32, n. 3, p. 126134, Sep 2007. ISSN 0301-4207.

CALDARELLI, C. E.; BACCHI, M. R. P. Fatores de influência no preço do milho no Brasil. Nova Economia, v. 22, 2012.

CALDARELLI, C.E. Integración y transmisión de precios entre los mercados de maíz y del pollo de engorde en Brasil. Revista Galega de Economía, vol. 22, n. 2, p. 219-234.diciembre 2013.

CEPEA. Perspectivas para o agronegócio em 2015. 2014. Disponível em: $<$ http:// www.cepea.esalq.usp.br/ comunicacao/Cepea_Perspectivas\%20Agrone g2015_relatorio.pdf. $>$. Acesso em: mar.2015

CEPEA. PIB do Agronegócio - Dados de 1994 a 2013. 2015. Disponível em: <http:// cepea.esalq.usp.br/ pib/ > Acesso em: mar.2015

CHEN, S.-T.; KUO, H.-I.; CHEN, C.-C. Modeling the relationship between the oil price and global food prices. Applied Energy, v. 87, n. 8, p. 2517-2525, Aug 2010. ISSN 0306-2619.

DICKEY, D.A.; FULLER, W. A. Likelihood ratio statistics for auto-regressive time series with a unit root. Econometrica, Oxford, v. 49, p. 1057-1072, 1981.

DICKEY, D.A.; FULLER, W.A. Distribution of the estimator for auto-regressive time series with a unit root. J ournal of the American Statistical

Association, Alexandria, v. 74, p. 427-431, 1979.

ELLIOTT, D.A.; ROTHENBERG, T. J .; STOCK, J . H. Efficient tests for an autoregressive unit root. Econometrica, Oxford, v.64, n.2, p. 813-836, 1996.

EMBRAPA. Custo de produção de aves. 2017. Disponível em https:// www.embrapa.br/ suinos-e-aves/ cias/ custos/icpfrango. Acesso em 31 mai. de 2017.

ENDERS, W. Applied econometric time series. 4. ed. New J ersey: J ohn Wiley, 2015, 480 p.ENGLE, R. F.; GRANGER, C. W. J . Cointegration and error correction: representation, estimation and testing. Econometrica, Oxford, v. 55, n. 2, p. 251-276, 1987.

FAO. Food and Agriculture Organization of the United Nations. FAOSTAT. 2016.

FMI. International Monetary Fund. Data and Statistics. 2014. Disponível em: < http:// www.imf.org/ external/ data.htm >. Acesso em: set. 2014.

FUNDAÇÃO GETÚTLIO VARGAS - FGV. FGV Dados. Disponível em:< http:// portalibre.fgv.br/ >. Acesso em 10 fev. 2017.

GRANGER, C. W. J . Investigating causal relations by econometric models and cross spectral methods. Econometrica, Oxford, v. 37, n. 3, p. 424-438, 1969.

HANSON, K.; ROBINSON, S.; SCHLUTER, G. Sectoral Effects of a World Oil Price Shock- Economy-Wide Linkages to the Agricultural Sector. J ournal of Agricultural and Resource Economics, v. 18, n. 1, p. 96-116, J ul 1993. ISSN 0162-1912. 
IEA.Instituto de Economia Agrícola. Banco de Dados, 2017. Disponível em: 〈http:// www.iea.sp.gov.br/ out/bancodedados.html>. Acesso em: out. 2014.

IPEADATA. Banco de dados - Regional. 2017. Disponível em: < http:// www.ipeadata.gov.br/ >. Acesso em: abr 2014.

JOHANSEN, S. Statistical analysis of cointegration vectors. J ournal of Economic Dynamics and Control, v. 12, p. 231-254, 1988.

LIBERA, A. A. D. Integração entre os mercados de milho e soja: uma análise através da transmissão de preços. 2009. 156 f. Dissertação (Mestrado em Agronegócios) - Programa de Pós-Graduação em Agronegócio, Universidade Federal do Rio Grande do Sul, 2009

LIU, W. S.; YUAN, J . S.; STEWART, C. N. Advanced genetic tools for plant biotechnology: Nature Reviews Genetics, v. 14, p. 781-793, 2013.

MUTUC, M.; PAN, S.; HUDSON, D. Response of Cotton to Oil Price Shocks. Southern Agricultural Economics Association Annual Meeting. Orlando 2010.

NAZLIOGLU, S.; SOYTAS, U. World oil prices and agricultural commodity prices: Evidence from an emerging market. Energy Economics, v. 33, n. 3, p. 488-496, May 2011. ISSN 0140-9883.

NG, S.; PERRON, P. Lag length selection and the construction of unit root tests with good size and power. Econometrica, Oxford, v.69, n. 6, p. 1519-1554, 2001.

OLIVEIRA J ÚNIOR, O. P.; WANDER, A.E.; FIGUEIREDO, R.S. Relação entre os preços do milho, da soja e da carne de frango no período de 2004 a 2013. In: Congresso da Sociedade Brasileira de Economia, Administracão e Sociologia Rural, 52, 2014, Goiânia. Anais.... Brasília-DF: SOBER, p. 1-16, 2014.

Osterwald-Lenum, M. A note with quantiles of the asymptotic distribution of the maximum likelihood cointegration rank test statistics. Oxford Bulletin of Economics and Statistics, v. 53n. 3, p. 461- 472, 1992.

PROFETA, G. A.; LIMA, J . E. D. Coordenação e transmissão de preços: o caso da cadeia do frango de corte no Brasil. In: Congresso da Sociedade Brasileira de Economia, Administração e Sociologia Rural, 50, Vitória.Anais...Vitória: Anais, 2012.

REBOREDO, J . C. Do food and oil prices co-move? Energy Policy, v. 49, p. 456467, Oct 2012. ISSN 0301-4215.

SAGHAIAN, S.H. The impact of the oil sector on commodity prices: correlation or causation? J . Agr. Appl. Econ., v.42, 477- 485, 2010.

WOODS, J .; WILLIAM, A.; HUGHES, J. K.; BLACK, M.; MURPHY, R. Energy and the food system. Philosophical Transactions of the Royal Society B-

Biological Sciences, v. 365, n. 1554, p. 2991-3006, Sep 2010. ISSN 0962-8436.

ZHANG, Q.; REED, M. Examining the Impact of the World Crude Oil Price on China's AgriculturalCommodity Prices: The Case of Corn, Soybean, and Pork: The Southern Agricultural Economics AssociationAnnual Meetings, 2008.

ZHANG, Z.; LOHR, L.; ESCALANTE, C.; WETSTEIN, M. Ethanol, Corn, and Soybean Price Relations in a Volatile Vehicle-Fuels Market. Energies, v. 2, n. 2, p. 320-339, J un 2009. ISSN 1996-1073. 